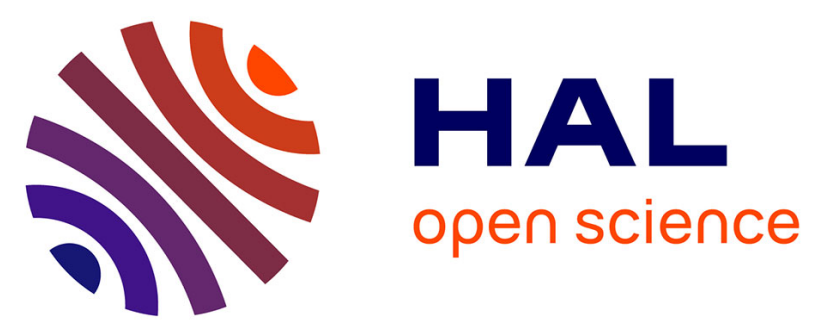

\title{
Integrated Component Data Model Based on UML for Smart Components Lifecycle Management: A Conceptual Approach
}

Luiz S. Durão, Helge Eichhorn, Reiner Anderl, Klaus Schützer, Eduardo De Senzi Zancul

\section{To cite this version:}

Luiz S. Durão, Helge Eichhorn, Reiner Anderl, Klaus Schützer, Eduardo De Senzi Zancul. Integrated Component Data Model Based on UML for Smart Components Lifecycle Management: A Conceptual Approach. 12th IFIP International Conference on Product Lifecycle Management (PLM), Oct 2015, Doha, Qatar. pp.13-22, 10.1007/978-3-319-33111-9_2 . hal-01377424

\section{HAL Id: hal-01377424 \\ https://hal.inria.fr/hal-01377424}

Submitted on 7 Oct 2016

HAL is a multi-disciplinary open access archive for the deposit and dissemination of scientific research documents, whether they are published or not. The documents may come from teaching and research institutions in France or abroad, or from public or private research centers.
L'archive ouverte pluridisciplinaire HAL, est destinée au dépôt et à la diffusion de documents scientifiques de niveau recherche, publiés ou non, émanant des établissements d'enseignement et de recherche français ou étrangers, des laboratoires publics ou privés. 


\title{
Integrated component data model based on UML for smart components lifecycle management: a conceptual approach
}

\author{
Luiz Fernando C. S. Durão ${ }^{1}$, Helge Eichhorn ${ }^{2}$, Reiner Anderl ${ }^{2}$, Klaus Schützer ${ }^{3}$, \\ Eduardo de Senzi Zancul ${ }^{1 *}$ \\ ${ }^{1}$ University of São Paulo, Brazil \\ luiz.durao@usp.br \\ ezancul@usp.br \\ ${ }^{2}$ Technische Universität Darmstadt, Germany \\ eichhorn@dik.tu-darmstadt.de \\ anderl@dik.tu-darmstadt.de \\ ${ }^{3}$ Methodist University of Piracicaba, Brazil \\ schuetzer@scpm.unimep.br \\ * to whom correspondence should be addressed
}

\begin{abstract}
Cyber-Physical Production Systems (CPPS) and Smart Products are considered key features in the development of the fourth industrial revolution. To create a connected environment in manufacturing based on CPPS, components must be able to store and exchange data with machines, and with other components and assemblies along the entire production system. At the same time, Smart Product features require that products and their components be able to store and exchange data throughout their entire lifecycle. Therefore, the aim of this paper is to present a preliminary integrated component data model based on Unified Modeling Language (UML) for the implementation of CPPS and Smart Product features. The development of the data model is based on requirements gathered both from the literature review and from corporate interviews with potential users. The results are still preliminary since the research results are part of a bigger research effort under an international collaboration network.
\end{abstract}

Keywords: Cyber-Physical Production Systems; Product Lifecycle Management; Data Model; Smart Products 


\section{Introduction}

The competitive situation for the manufacturing industry is marked by increasing product and process complexity associated with volatile markets and continuous shortening of innovation cycles. Both the increased complexity and the shortening of innovation cycles affect the development of new products, as well as the development of product related services. This scenario requires the development and management of more efficient and versatile production and logistic systems [1]. These current demands are driving the development of what is being called the fourth industrial revolution [2].

The world has already experienced three industrial revolutions. The trigger for the first one in the $18^{\text {th }}$ century was the widespread industrial use of steam engines. Less than 100 years later, manufacturing faced a second industrial revolution through the introduction of mass production systems. In the second half of the $20^{\text {th }}$ century, the introduction of programmable logic controllers in production inaugurated the third industrial revolution.

Recently, acatech (Deutsche Akademie der Technikwissenschaften - the German National Academy of Science and Engineering) proposed a program called Industrie 4.0 in order to lead the developments towards the fourth industrial revolution [2]. Industrie 4.0 considers the introduction of the Internet of Things and Services approaches in manufacturing environments in order to establish production networks integrating products, production processes, production resources, and logistic systems in the shape of Cyber-Physical Systems (CPS).

The aim is to enable the production of Smart Products within Smart Factories, which are capable of exchanging information autonomously, to trigger actions, and to control each other partner independently. Thus, Smart Factories shall employ completely new approaches to production, driven and controlled by Smart Products. This way, Industrie 4.0 challenges companies and research institutes to direct their efforts in the implementation of three key features [2]:

- Horizontal integration through value networks;

- End-to-end digital integration of engineering across the entire value chain;

- Vertical integration and networked manufacturing systems.

CPS will support the necessary collaboration among cyber environment and the surrounding physical world and its processes, constituting Cyber-Physical Production Systems (CPPS) [3].

The manufacturing industry is already in the midst of a globalized economy scenario, which requires companies to shorten the time to market for new products, reduce costs and cater to customer requirements by offering a wide variety of product customizations. Adaptability and innovation potential are becoming vital factors to improve competitiveness within the demanding environment of today's ever-changing markets [4]. However, the challenges arising from the fourth industrial revolution, such as the developments considered in the scope of Industrie 4.0, have brought about not only new requirements to be met, but also tremendous opportunities for research as well as for the introduction of new commercial solution that can give rise to completely new markets. The key question is how fast research institutes and the industry can react to this scenario. 
Planning to be prepared for the challenges and opportunities of the fourth industrial revolution, Brazilian and German partners started a collaborative research project called "Smart Components within Smart Production Processes and Environments SCoPE", supported by the BRAGECRIM (Brazilian-German Collaborative Research Initiative on Manufacturing Technology) Program. The project started in August 2014 and this paper aims to present the initial efforts in the development of an Integrated Component Data Model (ICDM), which should represent the necessary product and process information to support the communication of Smart Products within a Smart Production Environment.

This paper is structured in five sections. Section 2 presents requirements for the ICDM gathered from literature review while section 3 discusses empirical requirements gathered from the industry. Section 4 presents the features of the ICDM preliminary version. Finally, section 5 discusses conclusions and presents future research efforts.

\section{Data Model Requirements - Literature Review}

Industrie 4.0 is a new approach to the manufacturing chain that aims to integrate factory systems and to create a self-controlled, intelligent environment [5]. A controlled environment can provide lifecycle information and close the product information lifecycle loop [6]. It requires a flow of information connecting both the physical aspects of the factory floor and the data related to it, making up what is called CPPS [2].

In a CPPS, the components communicate with assembly stations and other components [7]. However, a CPPS is not about the union of the physical and the cyber. It is about the intersection of these worlds by transforming the physical into cyber and the cyber into physical [8]. Data is collected by the CPS at different levels resulting in a massive amount of information that needs to be structured in a model [9]. The component data model is a key element of models in CPPS [7].

The data model defines the component features and their relationships. It aggregates all relevant information of the product design [10]. The data model is not just about the product memory, but it also can influence production planning [7]. However, the link between design and process planning remains a main issue [11].

To cover different aspects of the literature on data models, a literature review was conducted. First, keywords were defined in relation to previous knowledge on the subject and the concepts of Industrie 4.0 and integrated manufacturing. The keywords, "Data model" and "CPS", were searched in the "Web of Science" and "Science Direct" databases considering a first filter that selected only articles of the manufacturing and computer science areas. This search resulted in approximately 6.000 articles.

A second filter was applied considering the similarity between the keywords of the database's articles and the present article keywords. The second iteration produced a total of 750 articles that required a third and deeper study of the article's abstract resulting in a total of 10 articles that were thoroughly analyzed. Considering the methodology proposed, it was possible to gather different data model propositions.

According to Dipper et al. [12], a data model should contain definitions of machine features in implicit terms such as depth, width, and length. Besides that, all features have an ID, the workpiece it belongs to and the related machine operations. Ramana et 
al. [10] suggest a geometric data model containing, besides ID, item coordinates, and item tolerance.

The inconsistency between the final component and the information available in the $\mathrm{CAD}$ database is a key issue to create an integrated platform [11]. Based on that, Zhou et al. [11] propose an integrated data model containing not only geometrical information, but also control data (key property, category, etc.), process data (hardness, roughness, etc.), function data (purpose, behavior, etc.) and management data (constraint, authority, etc.).

Following the premises of Zhou et al. [11], Piccard and Anderl in [13] propose an integrated data model that aims to reduce the gap between product model information and specific component data. Piccard and Anderl [13] include general management information, identification, product structure and assemblies, requirements and functionality, geometry, product manufacturing information, product configuration, product status and presentation as essential parts of a data model.

A data model certifies that the decisions are based on individual information. To ensure that, Strang and Anderl [7], propose a data model containing single part ID, single part dimension, single part tolerance, assembly ID, assembly station, assembler, assembling date, tools, order name, order specification and due date.

According to Kiritsis [6], it is fair to say that the connection between the product and the manufacturer is lost at the moment it is delivered to the customer. Identifying products individually helps to create a sustainable supply chain controlling product information at any time of the lifecycle. To close the Product Lifecycle Management (PLM) loop, Kiritsis [6] indicates that a data model should have the serial number, product type, product structure in addition to lifecycle phase and geometric information.

Companies spend a considerable amount of time trying to understand and apply the PLM approach. The correct representation of product information is a key factor in the implementation of PLM, according to Barbau et al. [14], who propose that a data model should include not only geometry information but also different aspects of the product. Considering these aspects, Barbau et al. [14] suggest that a data model should include function, behavior, structure, geometry, and material, assembly features, tolerances besides generalization, grouping, classification, and aggregation.

Information technology systems are used to deal with product data from the beginning of the development phase to the end of life. The majority of problems regarding the integration of data are caused by differences in the format of the information. Data models are employed to facilitate the portability and translation of information, according to Wang et al. [15]. To promote systematic communication, a data model should possess function, behavior, structure, geometry, and material, assembly features, tolerances in addition to generalization, grouping, classification and aggregation [15].

Analyzing the literature review, it is possible to define three main types of data model: manufacturing and assembly; integrated data model; and PLM data model. Manufacturing/assembly data model provides geometrical and process information in order to aid complete product manufacturing. The integrated data model provides information considering geometrical and management information aiming at mapping product status. PLM data model, on the other hand, proposes a data model containing 
information over the entire lifecycle of the product, from design to discard. Considering this classification, Table 1, summarizes the results and findings of the literature review.

Table 1. Data Model characteristics according to literature review

\begin{tabular}{|c|c|c|}
\hline Author & Data Model Characteristic & Data Model Types \\
\hline $\begin{array}{l}\text { T. Dipper, X. Xu, and P. } \\
\text { Klemm [12] }\end{array}$ & $\begin{array}{l}\text { Depth, width, length, ID, } \\
\text { workpiece, machine operation, } \\
\text { cutting strategies and cutting } \\
\text { parameters. }\end{array}$ & $\begin{array}{l}\text { Manufacturing/Assembly Data } \\
\text { Model }\end{array}$ \\
\hline $\begin{array}{l}\text { P. V. M. Ramana, K.V. Rao } \\
{[10]}\end{array}$ & ID, coordinates, and tolerance. & $\begin{array}{l}\text { Manufacturing/Assembly Data } \\
\text { Model }\end{array}$ \\
\hline D. Strang and R. Anderl [7] & $\begin{array}{l}\text { Single part ID, single part } \\
\text { dimension, single part } \\
\text { tolerance, assembly ID, } \\
\text { assembly station, assembler, } \\
\text { assembling date, tools, order } \\
\text { name, order specification and } \\
\text { due date }\end{array}$ & $\begin{array}{l}\text { Manufacturing/Assembly Data } \\
\text { Model }\end{array}$ \\
\hline $\begin{array}{l}\text { X. V. Wang and X. W. Xu } \\
\text { [15] }\end{array}$ & $\begin{array}{l}\text { Geometry, features, sketches, } \\
\text { manufacturing, information, } \\
\text { assembly information, and } \\
\text { drawings. }\end{array}$ & $\begin{array}{l}\text { Manufacturing/Assembly Data } \\
\text { Model }\end{array}$ \\
\hline $\begin{array}{l}\text { X. Zhou, Y. Qiu, G. Hua, H. } \\
\text { Wang, and X. Ruan. [11] }\end{array}$ & $\begin{array}{l}\text { Geometrical information, } \\
\text { control data (key property, } \\
\text { category, etc.), process data } \\
\text { (hardness, roughness, etc.), } \\
\text { function data (purpose, } \\
\text { behavior etc.) and } \\
\text { management data (Constraint, } \\
\text { authority, etc.). }\end{array}$ & Integrated Data Model \\
\hline $\begin{array}{l}\text { A. Piccard and R. Anderl } \\
\text { [13] }\end{array}$ & $\begin{array}{l}\text { General management } \\
\text { information, identification, } \\
\text { product structure and } \\
\text { assemblies, requirements and } \\
\text { functionality, geometry, } \\
\text { product manufacturing } \\
\text { information, product } \\
\text { configuration, product status } \\
\text { and presentation as essential } \\
\text { parts of the data model. }\end{array}$ & Integrated Data Model \\
\hline D. Kiritsis [6] & $\begin{array}{l}\text { Serial number, product type, } \\
\text { product structure besides } \\
\text { lifecycle phase and geometric } \\
\text { information. }\end{array}$ & PLM Data Model \\
\hline $\begin{array}{l}\text { R. Barbau, S. Krima, S. } \\
\text { Rachuri, A. Narayanan, X. } \\
\text { Fiorentini, S. Foufou, and R. } \\
\text { D. Sriram [14] }\end{array}$ & $\begin{array}{l}\text { Function, behavior, structure, } \\
\text { geometry and material, } \\
\text { assembly features, tolerances } \\
\text { besides generalization, } \\
\text { grouping, classification and } \\
\text { aggregation. }\end{array}$ & PLM Data Model \\
\hline
\end{tabular}


Following the literature review, empirical data was gathered in order to provide companies view on data model requirements.

\section{Data Model Requirements - Field Study}

Initial informal consultations with industry partners have shown that there is growing interest for Industrie 4.0 technologies, in general, and components as information carriers, in particular. However, there are many reservations regarding feasibility, data security, and protection of intellectual property. These issues will be discussed in more detail in this section to derive the industry-specific requirements for the ICDM.

It should be noted though that this is still a matter of investigation and more detailed and formalized results can be expected in the future. At the time of writing two industryoriented studies are being prepared for publication by Anderl et al. within the project "Effiziente Fabrik 4.0" [16] and in collaboration with the Verband Deutscher Maschinen- und Anlagenbau (VDMA, German Engineering Association) [17], which should provide additional information about industry requirements for smart components to the SCoPE project.

\subsection{Centralized and Distributed Data Storage}

It will possibly remain prohibitively expensive to embed significant amounts of data within every individual component in the near future. Therefore, centralized storage solutions for component data need to be investigated to enable quick adoption within the industry. On the other hand, mechatronic or cyber-physical components might already possess data handling capabilities and could easily accommodate additional component data (e.g. for maintenance purposes). Consequently, the ICDM needs to support centralized as well as distributed storage of component data.

\subsection{Multiple Means of Component Identification}

To connect centrally stored component data with the physical component, each component needs to be assigned a unique identifier (UID). Smart Production Units and Environments need to be able to retrieve automatically the component's UID. The consulted companies have expressed interest in enabling component traceability across the whole value creation chain. This might include physically demanding environments (e.g. hardening processes). Thus, the component identification technology must be suited to the production environments (e.g. Data Matrix codes instead of RFID for hightemperature environments).

\subsection{Infrastructure Integration}

Components as information carriers need to be integrated into the existing production and IT environments. This includes shop-floor systems such as 
Manufacturing Execution Systems (MES), field bus systems, and interfaces to programmable logic controllers (PLC) as well as office-floor systems like Enterprise Resource Planning (ERP), Product Lifecycle Management (PLM) and commercially available off-the-shelf databases.

\subsection{Data Security}

A potential area of conflict for many companies is the fact that while the smart components are produced and owned by the manufacturing company, external companies supply the equipment used in the manufacturing process. Since both parties have justified interest in ICDM data, the manufacturing company for improvement of their products and the equipment suppliers for the fine-tuning of production parameters, access controls must be implemented within the ICDM to enable collaborative use.

Especially if ICDM data is embedded into components in the future, strong encryption is mandatory to protect sensible data from unauthorized access.

\section{Preliminary Data Model}

Based on the literature review and industry's requirements it is possible to design a preliminary component data model considering that product information is gathered over the entire lifecycle. A component data model should contain, for instance, a unique identification, geometric information, process information, tolerance, product family and lifecycle phase. In addition, it should be able to integrate all the information coming from a wide range of sources over the lifecycle.

UML models provide stereotypes and constraints, together with syntax and semantics of the elements [18]. Considering the requirements gathered both from the literature review and from the field study, a preliminary ICDM is presented in Fig.1. The ICDM is organized in five packages: The core model that handles basic administrative tasks also provides an extension interface for the additional partial models order, privileges, production, and specifications (Fig.1).

Thus in the ICDM, a component is represented as an aggregation of its design specifications (specifications), production characteristics (production), access limitations (privileges) and customer's request (order) connected by an identification number as a primary key (core) to connect information over product lifecycle.

The product lifecycle starts with the properties provided by the design specifications such as the material characteristics, dimensions, and the production process plan that defines the planned activities to be executed within production. The specifications model is completed by requirements and simulation results from systems engineering contexts. The model is initialized with data obtained by interfacing with product data management (PDM) systems. 


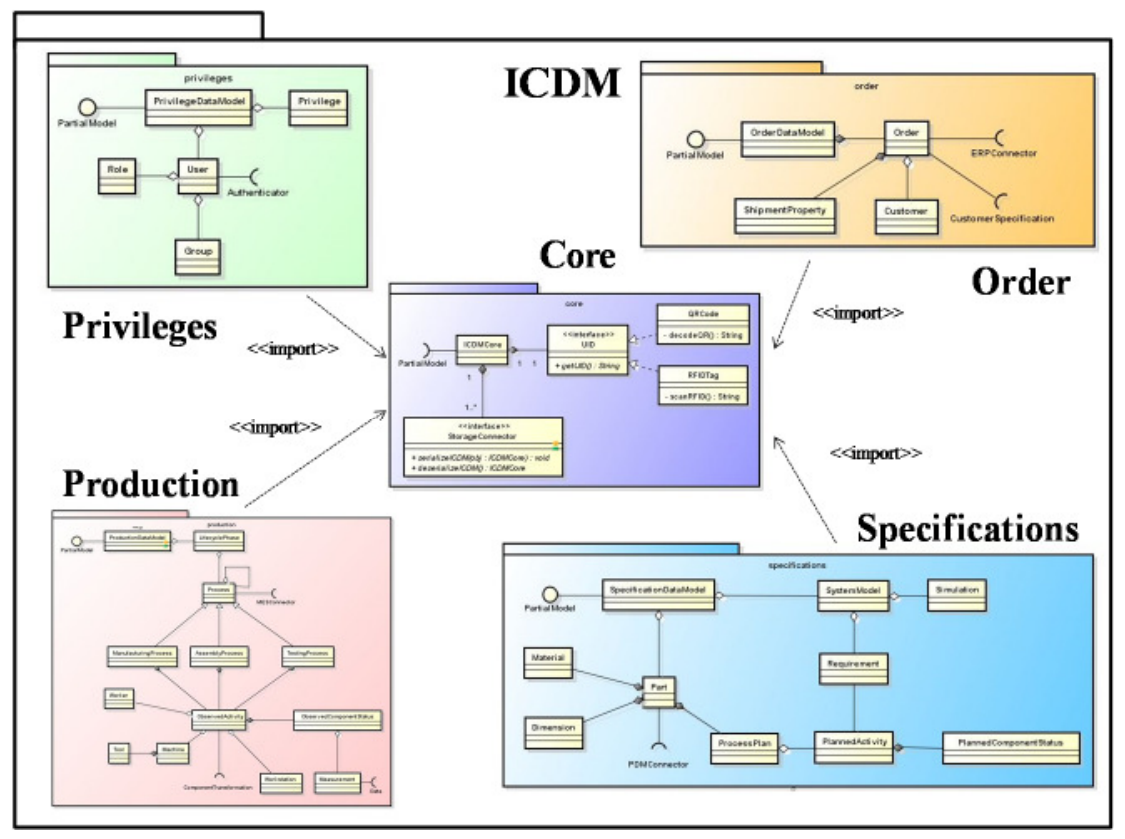

Fig. 1. Component data model using UML

The order partial model captures the information contained in enterprise resource planning (ERP) systems, including the customer for whom the component shall be produced and shipment information. Most importantly though the order data model captures customer-specific specifications and, therefore, enables customized production of the component within a smart production environment.

Throughout the physical production processes including manufacturing, assembly, and testing the production partial model is populated with data originating from manufacturing execution systems (MES). Process data such as responsible worker, utilized machines, workstations, and tools together with testing data such as measurements are captured to constitute observed production activities. This enables traceability of the component's production history and allows the optimization of future products and production processes.

To ensure that only authorized parties can access and modify the data within the ICDM the privileges partial model tracks all user (human users and smart systems) and user groups (departments, organizations, etc.) of component data together with their respective privileges. 


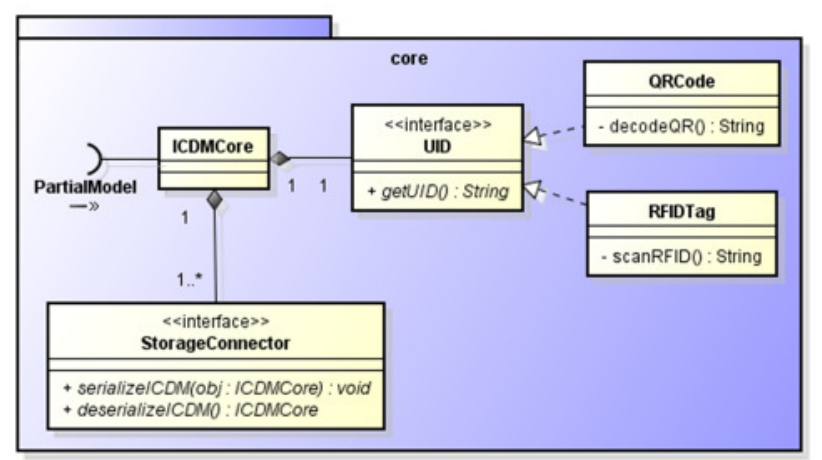

Fig. 2: Core package of the ICDM

Apart from integrating the aforementioned partial model, the proposed core package, detailed in Fig. 2 handles administrative tasks including the provision of the unique component identification through technologies such as RFID or QR code and physical storage of the ICDM data.

\section{Conclusions}

The research initiative Industrie 4.0 aims to be a driving force of the $4^{\text {th }}$ Industrial Revolution. Its purpose is to create an intelligent production chain connecting the physical product with data collected over the product lifecycle and turning this data into information. The connection between physical and cyber is achieved through the utilization of Cyber-Physical Systems. To create value from the collected data, it is structured within the Integrated Component Data Model.

The component data model aims to create a representation of the communication between the component and its surrounding environment over its entire lifecycle. At the same time, it has to fulfill the requirements suggested by the literature review together with the main concerns of the industry. Based on these characteristics, the ICDM with its partial models is proposed linking the designed specifications (materials, dimensions, process plan, etc.); the production characteristics (process, testing, tool, observed activities, etc.); access privileges; and order details such as customer specifications. Additionally, the proposed model provides unique component identification and technology-agnostic data handling.

This paper represents the initial effort on the development of the ICDM within the collaborative research project "Smart Components within Smart Production Processes and Environments - SCoPE" supported by the BRAGECRIM Program. Next steps in this research stream include further development of the ICDM, prototypical implementation, and advanced scenario testing. 


\section{Acknowledgments}

The authors thank the Coordination for the Improvement of Higher Education Personnel (Capes), the Brazilian National Council for Scientific and Technological Development (CNPq), and the German Research Foundation (DFG) for supporting related projects. The authors also thank the companies involved for providing real case applications.

\section{References}

1. D. M. and O. G. W. B. S. Schlund, "Industrie 4.0 - Volkswirtschaftliches Potenzial für Deutschland," in Bitkom - Berlin, 2014.

2. H. Kagermann, W. Wahlster, and J. Helbig, "Umsetzungsempfehlungen für das Zukunftsprojekt Industrie 4.0 - Abschlussbericht des Arbeitskreises Industrie 4.0," Berlin, 2013.

3. L. Monostori, "Cyber-physical production systems: Roots, expectations and R\&D challenges," in Procedia CIRP, 2014, pp. 9-13.

4. E. Westkämper and E. Zahn, "Wandlungsfähige Produktionsunternehmen". Berlin: Springer-Verlag, 2009.

5. R. Anderl, "Industrie 4.0 - Advanced Engineering of Smart Products and Smart Production," in $19^{\circ}$ Seminário Internacional de Alta Tecnologia, Piracicaba, 2014.

6. D. Kiritsis, "Closed-loop PLM for intelligent products in the era of the Internet of things," CAD Comput. Aided Des., vol. 43, no. 5, pp. 479-501, 2011.

7. D. Strang and R. Anderl, "Assembly Process driven Component Data Model in CyberPhysical Production Systems," in World Congress on Engineering and Computer Science, 2014, vol. II, pp. 22-24.

8. E. A. Lee, "CPS foundations," Des. Autom. Conf. (DAC), 2010 47th ACM/IEEE, pp. 737$742,2010$.

9. J. Lee, B. Bagheri, and H. Kao, "A Cyber-Physical Systems architecture for Industry 4 . 0based manufacturing systems," Manuf. Lett., vol. 3, pp. 18-23, 2015.

10. P. V. M. Ramana, K.V.; Rao, "Data and knowledge modeling for design process planning integration of sheet metal components," J. Intell. Manuf., vol. 15, pp. 607-623, 2004.

11. X. Zhou, Y. Qiu, G. Hua, H. Wang, and X. Ruan, "A feasible approach to the integration of CAD and CAPP," CAD Comput. Aided Des., vol. 39, no. 4, pp. 324-338, 2007.

12. T. Dipper, X. Xu, and P. Klemm, "Defining, recognizing and representing feature interactions in a feature-based data model," Robot. Comput. Integr. Manuf., vol. 27, no. 1, pp. 101-114, 2011

13. A. Piccard and R. Anderl, "Integrated Component Data Model for Smart Production Planning," in $19^{\circ}$ Seminário Internacional de Alta Tecnologia, Piracicaba, 2014.

14. R. Barbau, S. Krima, S. Rachuri, A. Narayanan, X. Fiorentini, S. Foufou, and R. D. Sriram, "OntoSTEP: Enriching product model data using ontologies," Comput. Des., vol. 44, no. 6, pp. 575-590, 2012.

15. X. V. Wang and X. W. Xu, "DIMP: an interoperable solution for software integration and product data exchange," Enterp. Inf. Syst., vol. 6, no. 3, pp. 291-314, 2012.

16. J. Anderl, R.; Abele, E.; Metternich, "Effiziente Fabrik - Effiziente Farbik 4.0." 2015 avaiable in http://www.effiziente-fabrik.tu-darmstadt.de/menue/index.de.jsp.

17. Verband Deutscher Maschinen- und Anlagenbau (Ed.), "Industrie 4.0 Forum." 2015.

18. X. Tang and H. Yun, "Data model for quality in product lifecycle," Comput. Ind., vol. 59, no. $2-3$, pp. $167-179,2008$. 